\title{
PENGEMBANGAN MEDIA PEMBELAJARAN CAD SEBAGAI PENUNJANG PERKULIAHAN PENDIDIKAN TEKNIK BANGUNAN DAN PEMBELAJARAN SMK JURUSAN BANGUNAN
}

\author{
Abdul Haris Setiawan \\ Prodi. Pend. Teknik Bangunan, Jurusan Pendidikan Teknik dan Kejuruan, FKIP, UNS \\ Kampus UNS Pabelan Jl. Ahmad Yani 200, Surakarta, Telp/Fax 0271718419 \\ email : $\underline{\text { haris@uns.ac.id }}$
}

\begin{abstract}
The objectives of this study are; (1) designing instructional media Computer Aided Design (CAD) for Pendidikan Teknik Bangunan (PTB) PTK FKIP UNS and Vocational High School (SMK) Building Construction Department, (2) to produce a viable medium of learning CAD, (3) determine whether the CAD design of learning media can improve the competence of students in PTB and vocational students Building Construction Department.

The designing of instructional Media is made at Vocational High School (SMKN 5 Surakarta) given in the form of video instructional media learning is needed. The method used in this research is the development of research methods. Criteria for success of this study refers to the successful implementation of product testing. The success include process and outcome indicators: (1) it is compliance with aspects of the substance of learning, aspects of media and instructional aspects, (2) It fits for use as a medium of learning, (3) vocational students receive as an innovative product in the learning, (4) it can help Vocational High School students (SMK) in learning more effective and efficient.

The conclusion of this study include: (1) CAD design of instructional media for PTB and SMK is carried out in accordance with the procedures, (2) media products of CAD Learning Media is worth to use in PTB FKIP UNS and SMK Building Construction Department, (3) CAD instructional media products can increase the competence of student at PTB and vocational students Building Construction Department.
\end{abstract}

Keywords: Multimedia learning, CAD, instructional media

\section{PENDAHULUAN}

Pakar pendidikan mengidentifikasikan hal-hal yang dapat mempengaruhi hasil belajar adalah faktor yang berasal dari dalam siswa dan faktor yang berasal dari luar diri siswa. Suharsimi Arikunto (1990:20) berpendapat bahwa: "Faktorfaktor yang mempengaruhi hasil belajar dapat dibedakan atas dua jenis yaitu sumber dari dalam diri manusia yang belajar, yang disebut sebagai faktor internal, dan faktor yang bersumber dari luar diri manusia yang belajar, yang disebut faktor eksternal.

Kondisi pembelajaran CAD (computer Aided Design) menggambar bangunan gedung menggunakan program aplikasi komputer di berbagai jenjang pendidikan (Perguruan tinggi, SMK Bangunan dan pendidikan vokasi yang relevan) membutuhkan perhatian khusus. CAD merupakan dasar pengetahuan dalam kompetensi menggambar teknik. Materi ini harus dikuasai oleh semua peserta didik yang mempelajari bidang teknik bangunan. Pembelajaran CAD PTB JPTK FKIP UNS dilaksanakan dengan dibagi menjadi tiga kelompok karena keterbatasan sarana komputer. Pembagian kelompok ini menyebabkan efisiensi pembelajaran menjadi berkurang. Dosen diharuskan mengajar sebanyak tiga kali dalam satu minggu dengan materi yang sama. Banyaknya jumlah pertemuan sebenarnya bukan masalah utama bagi dosen, namun penyampaian materi yang sama dan berulang-ulang sering kali dirasakan sebagai pemborosan waktu dan tenaga. Dari hasil pengalaman tersebut muncul sebuah gagasan/ide untuk merancang media pembelajaran yang berupa video pembelajaran untuk mendukung perkuliahan CAD.

Dengan dukungan media pembelajaran CAD, dosen dapat menyampaikan materi ajar yang sama dengan memutar video pembelajaran yang sudah disiapkan sebelumnya disamping penyampaian materi tambahan yang tetap disampaikan dalam pembelajaran berupa motivasi dan penekanan-penekanan kembali pada hal-hal penting yang harus diingat mahasiswa sehingga mahasiswa benar-benar memahami materi yang telah disampaikan. Media pembelajaran ini dapat dilihat dalam bentuk VCD dan dapat digunakan berkali-kali sesuai kebutuhan, selain itu materinya juga dapat diseragamkan tanpa mengurangi sedikitpun materi yang akan disampaikan disetiap kelasnya. Akan tetapi dapat ditambahkan sesuai dengan 
perkembangan materi yang ada dengan media konvensional.

Kegiatan belajar mengajar ditentukan oleh dua faktor yang berasal dari dalam siswa dan faktor yang berasal dari luar diri siswa. faktor luar terdiri dari lingkungan dan instrumental (bahan pelajaran, pengajar, media pembelajaran, sarana dan fasilitas pembelajaran dan administrasi), sedangkan faktor dalam dipengaruhi oleh fisiologi dan psikologi.

Salah satu upaya eksternal untuk meningkatkan pemahaman dan hasil belajar mahasiswa terhadap materi pelajaran adalah melalui penggunaan media pembelajaran berupa video. Video pembelajaran $\mathrm{CAD}$ merupakan salah satu alat bantu pembelajaran yang dapat dimanfaatkan untuk memperjelas pembelajaran. Materi ajar yang akan disampaikan itu bisa disiapkan dirumah dan bisa diputar kembali saat proses pembelajaran. Hal ini lebih efisien, interaktif dan komunikatif sehingga dapat menumbuhkan sikap positif pada peserta didik.

Dari beberapa hal di atas, permasalahan yang ada dapat digambarkan dalam diagram kerangka berfikir sebagai berikut :

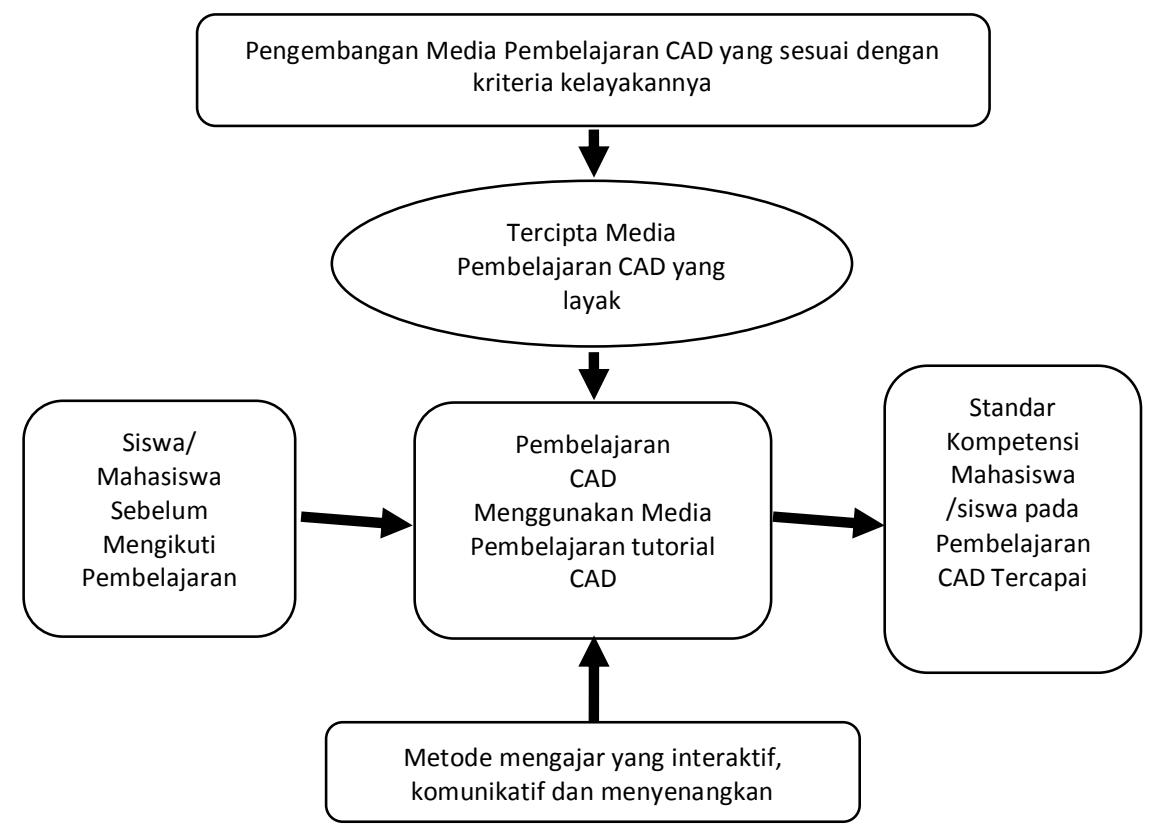

Gambar 1. Kerangka Berfikir

Masalah yang akan diteliti dalam penelitian ini dapat dirumuskan sebagai berikut :

1. Bagaimanakah pengembangan media pembelajaran CAD Prodi PTB dan pembelajaran SMK Jurusan Bangunan yang layak? (tim peneliti pengembangan media)

2. Mengetahui apakah hasil perancangan media pembelajaran CAD dapat menunjang Perkuliahan Pendidikan Teknik Bangunan dan Pembelajaran SMK Jurusan Bangunan? (tim peneliti survey)

3. Bagaimana penerapan media pembelajaran CAD pada model pembelajaran di kelas dengan beberapa model pembelajaran yang berbeda? (penelitian tindakan kelas/ action research, kelanjutan di beberapa lokasi dan model yang lebih bervariasi)

\section{METODOLOGI PENELITIAN}

Metode penelitian gabungan dari beberapa Metode penelitian yang dilaksanakan secara bertahap sesuai dengan tahapan pelaksanaannya. Metode pengembangan (Research and Development), menggunakan model prosedural yang bersifat deskriptif yang dilaksanakan pada tahap awal dengan mengembangkan media pembelajaran CAD. Tahap berikutnya adalah metode action research (PTK), merupakan penerapan media dengan berbagai model pembelajaran yang disesuaikan dengan media CAD. Selanjutnya tahap survey yang dilaksanakan secara kuantitatif sebagai justifikasi penggunaan media di masyarakat/institusi pendidikan dengan beberapa pendekatan. Penelitian evaluasi keterlaksanaan pembelajaran dimungkinkan dilaksanakan jika dianggap perlu, sampai dengan pengembangan lebih lanjut media dengan revisi-revisi yang 
didapat dari penelitian survey dan evaluasi yang telah terlaksana.

Setelah produk media pembelajaran selesai dirancang, selanjutnya dilakukan uji coba pada media pembelajaran ini, sehingga kualitas Produk yang dikembangkan betul-betul teruji secara empiris. Desain evaluasi tersebut digambarkan sebagai berikut:

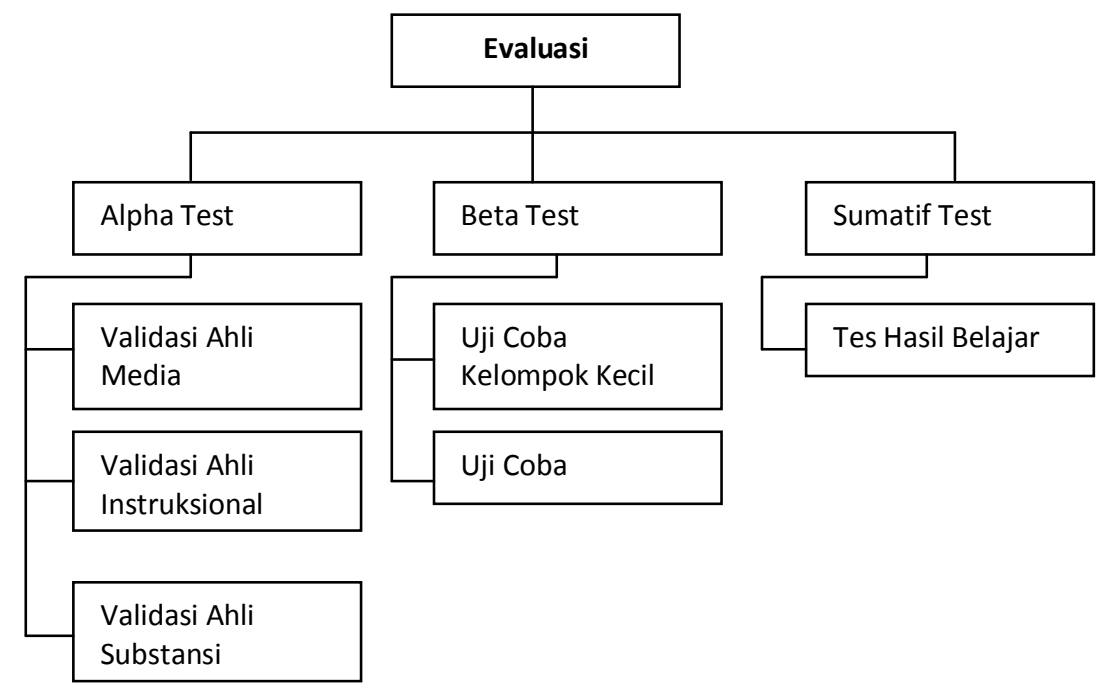

Gambar 2. Desain evaluasi media pembelajaran CAD

\section{Alpha Test}

\section{a. Ahli media}

Validasi produk dilakukan dengan pengisian angket oleh ahli media. Angket yang digunakan berisikan peryataan yang terdiri dari aspek audio visual, desain media, Navigasi, dan Waktu. Angket untuk ahli media memiliki 12 butir peryataan.Hasil pengisian angket merujuk pada validnya produk yang dibuat. Dapat dipersentasikan hasil ketercapaian video pembelajaran menuju kata valid adalah sebesar $78,3 \%$. Dengan demikian video yang dibuat sudah mendapatkan Validasi dari ahli media hingga hasilnya valid dan layak digunakan.

\section{b. Ahli Instruksional}

Ahli instruksional pendidikan memberikan penilaian valid tidaknya produk yang dibuat dengan menggunakan angket. Angket yang digunakan berisikan peryataan yang terdiri dari aspek motivasi, kurikulum, rumusan dan realistis. Angket untuk ahli Intuksional memiliki 5 butir peryataan. Dapat diprosentasekan hasil ketercapaian video pembalajaran menuju kata valid adalah sebesar $84 \%$. Dengan demikian video yang dibuat sudah mendapatkan Validasi dari ahli Instruksional hingga hasilnya valid dan layak digunakan.

\section{c. Ahli Substansi}

Angket yang digunakan berisikan peryataan yang terdiri dari aspek Kebenaran konsep, isi materi, dan pembelajaran. Angket untuk ahli subtansi memiliki 10 butir peryataan. Hasil pengisian angket merujuk pada validnya produk yang dibuat. Dapat dipersentasikan hasil ketercapaian video pembalajaran valid adalah sebesar $82 \%$. Dengan demikian video yang dibuat sudah mendapatkan Validasi dari ahli subtansi hingga hasilnya valid dan layak digunakan.

\section{Beta Test}

\section{a. Uji Terbatas / Kelompok Kecil}

Setelah produk mendapatkan validasi oleh para ahli, selanjutnya dilakukan uji terbatas dengan menampilkan produk berupa video pembelajaran AutoCAD menggambar tampak dan potongan pada bangunan. Sampel diambil dari mahasiswa Prodi PTB dan siswa kelas XI TKB semester satu SMK N 5 Surakarta. Peneliti menggunakan purposive sampling untuk mendapatkan informasi secara mendalam dan dapat dipercaya untuk menjadi sumber data yang dibutuhkan peneliti. Peneliti menetapkan 5 mahasiswa Prfodi PTB dan tim SMK dengan 4 siswa dan 1 guru pengampu mata pelajaran AutoCAD kelas XI TKB SMKN5 Surakarta. Pada siswa SMK wawancara dilakukan pada beberapa siswa, antara lain: Febri Andi Herlambang, Yudi Setiawan, Ryan Abrianto, dan Wisnu Dwi S. Uji coba dilakukan pada tanggal 06 Oktober 2012. Dan 1 guru pengampu mata pelajaran AutoCAD yaitu Margono S,Pd. pada tanggal 08 Oktober 2012. Pengujian dilakukan 
untuk mendapatkan informasi tentang kelayakan video pembelajaran ini sebagai media bantu dalam pelajaran.

\section{b. Uji Lapangan}

Setelah produk mendapatkan pengujian terbatas, selanjutnya dilakukan uji lapangan dengan menampilkan produk berupa video pembelajaran Auto Cad. Sampel diambil dari mahasiswa Prodi PTB yang mengikuti mata kuliah CAD 2D dan siswa kelas XI TKK semester ganjil SMK N 5 Surakarta (tim peneliti mahasiswa). Pengujian dilakukan untuk mendapatkan informasi tentang kelayakan video pembelajaran ini sebagai media bantu dalam pelajaran.

Dalam pengujian lapangan ini peneliti menggunakan penyebaran angket untuk mencari informasi seberapa layak video ini digunakan sebagai media bantu dalam penyampaian mata kuliah CAD 2D di Prodi PTB dan mata pelajaran Auto Cad. Penyebaran angket ditujukan pada 50 mahasiswa Prodi PTB yang mengikuti mata kuliah CAD 2D. Angket berisikan 21 butir pertanyaan yang mencakup pada aspek audio visual, alat, waktu, isi, dan motivasi.

\section{SIMPULAN}

1. Perancangan media pembelajaran $\mathrm{CAD}$ telah terlaksana berdasarkan kriteria kualitas media pembelajaran yang baik

2. Hasil perancangan media pembelajaran CAD layak digunakan pada Mata Kuliah CAD 2d.

3. Hasil perancangan media pembelajaran $\mathrm{CAD}$ dapat meningkatkan kompetensi mahasiswa pada mata kuliah CAD 2d.

4. Perancangan video pembelajaran CAD dapat membantu siswa SMK dalam memahami materi dengan baik.

5. Media pembelajaran CAD dengan model-model Pembelajaran dapat memperbaiki atau meningkatkan: hasil belajar dengan ketuntasan belajar yang diperoleh dari nilai kompetensi siswa, efektivitas pembelajaran dengan adanya peningkatan dari setiap siklus baik dari ranah afektif maupun psikomotorik.

6. Terdapat perbedaan hasil belajar kognitif siswa SMK yang diajar menggunakan metode berbasis video pembelajaran dengan konvensional mata pelajaran autocad.

\section{DAFTAR PUSTAKA}

Ena, Ouda Teda. (2001). Membuat media pembelajaran interaktif dengan piranti lunak presentasi. Yogyakarta: Indonesia Language and Culture Intensive Course Universitas Sanata Darma.

Enterprise, Jubile. (2008). Teknik membuat video tutorial dengan camtasia studio 5.0. Jakarta: Elex Media Komputindo.

Gagne, R. M. \& Briggs, L.J.(1979). Principles of instructional design. New York: Holt, Rinehart and Winston.

Henson, K.T \& Eller, B.F.(1999). Educational psychology for effective teaching. Boston: Wadsworth Publishing Company.

Klein, S.B.(2002). Learning principles and applications. New York: Mc. GrawHill.

Lakoro, Rahmatsyam. (2004). Iklan dan Fungsi media yang terlupakan. http://www.its.ac.id/personal/show pub likasi.php?id $=710$

Leahy, W., \& Sweller, J. (2010). The effect of length of auditory instructions on the modality effect: The transitory information effect. The paper

presented at the 4th International Cognitive Load Theory Conference, 22-25 November 2010, Hong Kong and Macau.

Mayer, R. E., Hegarty, M., Mayer, S., \& Campbell, J. (2005). When static media promote active learning: Annotated illustrations versus narrated animations in multimedia instruction. Journal of Experimental Psychology: Applied, 11, 256-265.

Mayer, R. E. (2009). Multimedia learning (2nd $E d$.). New York, NY: Cambridge University Press.

Mouli, G.J.(1973). Psychology for effective teaching $\left(3^{\text {rd }} e d\right)$. New York: Holt, Rinehart and Winston

Oemar Hamalik.(2008). Perencanaan pengajaran berdasarkan pendekatan sistem. Jakarta: PT. Bumi Aksara.

Oemar Hamalik.(2004). Psikologi belajar dan mengajar. Bandung: Sinar Baru Algesindo.

Purwanto.(2004). Psikologi pendidikan. Bandung: Remaja Rosdakarya

Rumberger, Russell W. , \& Palardy, Gregory J. (2005). Test Scores,Dropout Rates, and transfer Rates as Alternative Indicators 
of High School Performance, American Educational Research Journal volume 42, Number 1-Spring 2005

Saiful Bahri Djamarah. (1994). Strategi Belajar Mengajar. Jakarta : Rineka Cipta

Siaahan, S. (2007). Media Pembelajaran : Pemahaman dan Pemanfaatannya Dalam Kegiatan Pembelajaran. Jurnal teknodik 20 : 73-98

Slava Kalyuga (2011). Effects of information transiency in multimedia learning, International Journal of Procedia Social and Behavioral Sciences 30 (2011) $\quad 307 \quad-\quad 311$. www.sciencedirect.com

Slameto.(2003). Belajar dan faktor-faktor yang mempengaruhinya. Jakarta: Rineka Cipta.

Sopah, D.(2000). Pengaruh model pembelajaran dan motivasi berprestasi terhadap hasil belajar. Jurnal Pendidikan dan Kebudayaan 022 tahun ke-5 Maret: 121-137.

Sudarwan Danim.(2002). Inovasi pendidikan: dalam upaya peningkatan profesionalisme tenaga kependidikan. Bandung: Angkasa

Sugiyono. (2008). Metode penelitian kuantitatif kualitatif dan $R \& D$. Bandung: Alfa Beta 